\title{
ASPECTO INERENTE E PASSADO IMPERFECTIVO NO PORTUGUÊS: ATUAÇÃO DOS PRINCÍPIOS DA PERSISTÊNCIA E DA MARCAÇÃO
}

\author{
Raquel Meister Ko. FREITAG*
}

- RESUMO: Neste texto são apresentados indícios da ação dos princípios da persistência (HOPPER, 1991) e da marcação (GIVÓN, 2001) na gramaticalização das formas de expressão do passado imperfectivo no português. O controle do aspecto inerente ao verbo em um modelo quantitativo apontou que o traço aspectual [dinamismo] determina as associações entre formas na expressão do passado imperfectivo, por conta do histórico aspectual de PPROG, marcado com relação direta com o traço [+ dinâmico], e IMP, associado com o traço [- dinâmico] por conta do seu histórico de marcar distanciamento. Esses resultados sugerem que a persistência e a marcação podem ser consideradas motivações convergentes no processo de variação na expressão do passado imperfectivo.

- PALAVRAS-CHAVE: Passado imperfectivo. Gramaticalização. Motivações convergentes.

\section{Introdução $^{1}$}

O valor semântico-discursivo de passado imperfectivo, no português falado no Brasil, apresenta duas formas de realização: a forma de pretérito imperfeito do indicativo (IMP) e a forma perifrástica, constituída pelo auxiliar estar acompanhado do morfema de pretérito imperfeito do indicativo e verbo principal no gerúndio (PPROG), como em (1) e (2) respectivamente:

(1) "Na época que eu mais precisei dele, que eu mais precisava de um apoio, foi quando a minha mãe morreu." (SC FLP FAP 03). ${ }^{2}$

(2) "Aí também foi na época que a gente voltou, a gente estava precisando economizar pra começar nossa vida." (SC FLP FAP 01).

* UFS - Universidade Federal de Sergipe. Centro de Educação e Ciências Humanas - Núcleo de Pós-Graduação em Letras. São Cristóvão - SE - Brasil. 49100-000 - rkofreitag@uol.com.br

1 Este texto é parte revisada e ampliada da tese de doutorado A expressão do passado imperfectivo no português: variação/gramaticalização e mudança, sob orientação da prof. ${ }^{a}$ Edair Maria Gorski, defendida em 2007, na Universidade Federal de Santa Catarina.

2 O código ao final dos dados refere-se à indicação da fonte, a amostra de Florianópolis do banco de dados do Projeto VARSUL - Variação Linguística Urbana da Região Sul do Brasil -, de onde foram extraídos. Amostras do áudio dos dados podem ser conferidas em Projeto VarSul (2010). 
O passado imperfectivo ${ }^{3}$ é uma função caracterizada temporalmente pela relação de ordenação e sobreposição e aspectualmente, pela relação de inclusão. Em relação ao tempo, o passado imperfectivo refere-se a uma situação anterior ao momento de fala e simultânea ao ponto de referência, também anterior, daí a noção de passado. Em relação ao aspecto, o passado imperfectivo refere-se a uma situação cujo intervalo inclui o ponto de referência, o que manifesta o andamento da situação em relação à referência, daí a noção de imperfectividade. Em (1), a situação precisava é anterior ao momento de fala e ocorre concomitantemente a um ponto de referência, estabelecido pela oração subordinada adverbial temporal "quando a minha mãe morreu". A situação, apesar de já ter ocorrido, é apresentada como em andamento em relação ao ponto de referência; na oração anterior "Na época que eu mais precisei dele", o mesmo item lexical é apresentado como perfectivo (valor associado à forma de pretérito perfeito). Em (2), a situação estava precisando também se refere a uma situação passada - anterior ao momento de fala - e concomitante a um ponto de referência, também passado: "Aí também foi na época que a gente voltou". Observe-se que, com o mesmo item lexical, no mesmo contexto, com o mesmo tipo de ponto de referência (oração temporal), duas formas para expressar passado imperfectivo podem ser utilizadas: IMP e PPROG. Quando as formas IMP e PPROG apresentam essas propriedades semântico-discursivas, podemos considerá-las como variantes na expressão do passado imperfectivo. A análise da variação nos níveis gramaticais mais altos (além da fonologia) costuma se deparar com problemas relacionados à frequência, à equivalência semântica e à necessidade de interface teórica para dar conta do fenômeno (FREITAG, 2009), sendo necessário partir em busca de explicações/ motivações a variação destas formas. Podemos, no caso do passado imperfectivo no português, aventar a hipótese de atuação de dois princípios funcionais de organização da língua: o princípio da persistência e o princípio da marcação.

De acordo com Hopper (1991), quando uma forma sofre gramaticalização, passando de lexical a gramatical, alguns traços de seu sentido lexical original tendem a continuar, e detalhes da sua história lexical podem se refletir no

\footnotetext{
No domínio da imperfectividade, o passado imperfectivo recobre os valores progressivo em (1); iterativo em (2); e habitual em (3), além de casos de ambiguidade aspectual (imperfectivo genérico, valor em que a especificidade aspectual não é relevante nem para o falante nem para o ouvinte naquele contexto comunicativo, em (4) (FREITAG, 2007).

(1) "Era dez da noite, a mãe fazia a janta, quando a gente recebeu a notícia que ele se acidentou." (SC FLP $\mathrm{MBC} 23)$.

(2) "Setenta e três. Foi campeão pelo Figueirense. E era Figueirense fanático e do Flamengo. Quando o Flamengo perdia, ele quebrava o rádio." (SC FLP MAC 19).

(3) "Então a gente perdia tempo à beça esperando que viesse outro ônibus. O ônibus quebrava toda hora, toda hora. Mas era a maior dificuldade, sabe? pra gente se locomover de ônibus." (SC FLP MAC 18).

(4) "E o meu avô estava brigando com eles, né". (SC FLP FAP 01). A situação pode ser interpretada como uma única briga que se estende (valor progressivo) ou uma briga habitual.
} 
condicionamento da sua distribuição gramatical; esse é, basicamente, o princípio da persistência.

O princípio da marcação, por sua vez, está associado à complexidade e à previsibilidade: significados e funções complexos e menos previsíveis tendem a ser codificados através de formas compostas por mais "marca", isto é, formas compostas por um maior número de material linguístico - fonemas, morfemas, palavras. Nessa linha, Givón (2001) aponta a existência de uma relação icônica entre o processamento cognitivo da língua e sua representação material no discurso, no sentido de que processos de produção mais complexa são codificados linguisticamente através de formas materiais mais marcadas. Segundo Givón (2001), formas que pertencem a uma mesma categoria gramatical diferenciam-se quanto ao grau de marcação: as marcadas tendem a ser utilizadas em contextos cognitivo-comunicativos complexos; por sua vez, as formas não marcadas tendem a ser utilizadas em contextos mais simples. Ou seja, as formas gramaticais podem vir a receber usos especializados, particularizados para certos contextos em razão de seu grau de marcação linguística. Neste texto, testamos a hipótese de que o aspecto inerente ao verbo atua no direcionamento da variação semântico-discursiva entre IMP e PPROG, sob os efeitos dos princípios da persistência e da marcação. Assim, nas seções a seguir, primeiramente são discutidos modelos para o controle do aspecto inerente ao verbo, especificamente os modelos de Vendler (2005), Rothstein (2004) e de Bertinetto (2001); na sequência, os resultados quantitativos para a expressão do passado imperfectivo são analisados, a fim de corroborarem indícios da ação do princípio da persistência e da marcação na gramaticalização das formas de expressão do passado imperfectivo no português.

\section{Hipóteses para o aspecto inerente}

O aspecto inerente ao verbo, ou acionalidade, ou aktionsart, refere-se não à estrutura temporal interna da situação, mas ao tipo de situação propriamente. ${ }^{4} \mathrm{E}$ um traço próprio do item lexical; uma propriedade oriunda do léxico conceitual, mas que interage com o componente gramatical. Partindo da premissa de que a expressão do aspecto é composicional - ou seja, constituída pela interação entre o traço aspectual oriundo do léxico, o morfema gramatical verbal, adjuntos adverbiais e contexto comunicativo -, o aspecto inerente é o nível mais estrito da aspectualidade. Vejamos, primeiramente, modelos teóricos para o aspecto inerente com a finalidade de definir hipóteses para testar o papel deste componente para a variação na expressão do passado imperfectivo em português.

4 Há discussões na literatura acerca das semelhanças e diferenças entre aspecto inerente ao verbo, acionalidade, aktionsart, bem como profusão de terminologias; não é objetivo entrar na discussão. 
A primeira proposta de classificação aspectual é a de Vendler (2005), que considera as situações quanto ao desenvolvimento, ao tempo verbal e às suas relações com os modificadores temporais. Resumindo, as classes de Vendler (2005) são: i) estado - atribui propriedade ao sujeito: ser brasileiro, acreditar em algo, saber inglês, amar alguém -; ii) achievement-expressa mudança instantânea de estado de coisas: alcançar o cume da montanha, reconhecer alguém, vencer a corrida -; iii) atividade - expressa o desenvolvimento de uma situação homogênea e contínua: correr, cantar, nadar - e iv) accomplishment - expressa o desenvolvimento de uma situação com delimitação (ponto final): atravessar a rua, escrever uma carta, correr 500 metros.

A segunda proposta de classificação é a de Rothstein (2004, p. 12), que desdobra as classes aspectuais de Vendler (2005) em duas propriedades - se a situação denotada por um predicado qualquer tem um ponto final natural, ou seja, se possui um thélos, um ponto de culminação, e se a situação pode ser analisada quanto ao seu progresso no tempo, ou seja, se pode ser dividida em fases - conforme o quadro 1.

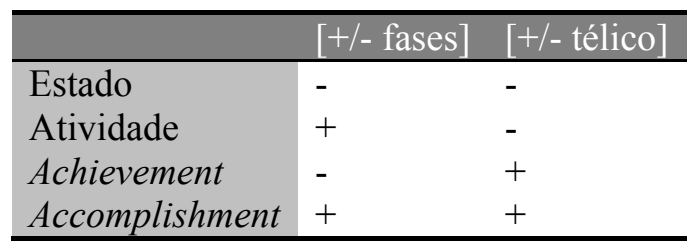

Quadro 1 - Propriedades das classes aspectuais

Fonte: Rothstein (2004, p.12).

Observe-se que estados e achievements são classes aspectuais que, de acordo com essa proposta, não poderiam ocorrer com IMP ou PPROG quando expressam passado imperfectivo. Mas realizações como (3), em que duas situações pertencentes à classe dos estados codificam passado imperfectivo, são possíveis.

(3) "A gente, criança e estava imaginando, achava que ele estava lá." (SC FLP 01).

Já a combinação entre achievements e IMP e PPROG não é possível. Uma situação como a de (4) não pode ser considerada um achievement apesar de alcançar o topo da montanha ser um exemplo clássico de achievement.

(4) Darla alcançava o topo da montanha quando houve uma avalanche.

É a combinação entre o conteúdo lexical do verbo, a construção que caracteriza aspecto gramatical imperfectivo e o argumento interno do predicado que resulta em um accomplishment. 
De acordo com Rothstein (2004), a telicidade, traço inerente do verbo (lexical conceitual), estabelece relações com a perfectividade/imperfectividade, dimensão qualitativa do aspecto gramatical (conforme as proposta de Castilho (2003) e de Wachowicz (2003)). Embora as noções de aspecto gramatical e aspecto inerente sejam independentes, parece haver convergência entre aspecto imperfectivo e verbos atélicos e aspecto perfectivo e verbos télicos. Os verbos télicos expressam ações que tendem a um ponto culminante para que a situação realmente ocorra, como matar, morrer, cair, engolir etc. Verbos atélicos expressam uma ação em sua duração, independente de um ponto culminante para que se considere a existência da situação, como mastigar, viver, escrever, acompanhar, etc. Verbos télicos tendem a atualizar aspecto perfectivo e verbos atélicos tendem a atualizar aspecto imperfectivo, apesar de flexão, adjuntos e complementos interagirem - dada a noção composicional - e provocarem mudança de uma categoria a outra; é o que acontece com achievements que, quando expressam passado, ao serem combinados com a morfologia de aspecto imperfectivo, resultam em accomplishments, originando a incongruência aspectual.

Por conta da possibilidade de correlação entre telicidade $\rightarrow$ perfectividade, e atelicidade $\rightarrow$ imperfectividade, os aspectos inerente e gramatical aparentemente seriam redundantes.

A fim de resolver o problema, Bertinetto (2001) apresenta uma proposta que pretende desfazer a aparente redundância da codificação aspectual. Ele retoma a classificação vendleriana e a caracteriza, não por duas - como faz Rothstein (2004) -, mas por três propriedades interrelaciondadas: duratividade, dinamicidade e homogeneidade, as quais estão apresentadas no quadro 2.

\begin{tabular}{cccc}
\hline & Durativo & Dinâmico & Homogêneo \\
\hline Estados & + & - & + \\
Atividades & + & + & + \\
Achievements & - & + & - \\
Accomplishments & + & + & - \\
\hline
\end{tabular}

Quadro 2 - Propriedades das classes aspectuais

Fonte: Rothstein (2004, p.12).

A propriedade da homogeneidade refere-se à ausência de um limite interno inerente em uma dada situação, sendo fundamental para a distinção entre telicidade e atelicidade. Situações atélicas - estados e atividades - são definidas como: se uma situação $\underline{\underline{S}}$ ocorre num intervalo de tempo I, então $\mathbf{s}$ também ocorre em cada subintervalo de I. Ou seja, uma situação homogênea é aquela que não muda de natureza. Em contraponto, accomplishments e achievements não são homogêneos porque são télicos. 
A dinamicidade é uma propriedade caracterizada a partir da observação dos estados. Situações de estado são "densas", não apresentam nenhum desenvolvimento interno e recebem o traço [-dinâmicas], o que, em tese, justifica o barramento do emprego do imperfectivo progressivo (no caso específico, de passado imperfectivo), mas não dos outros tipos de situação: achievements, accomplishments e atividades são situações [+ dinâmicas].

Bertinetto (2001) propõe que a sequência mínima de gestos que instancia uma dada situação dinâmica seja denominada de átomo dinâmico e os estados, compostos por átomos estáticos. Átomos dinâmicos correspondem à granularidade mínima definida pela situação e, por isso, não são divisíveis indefinidamente. Os átomos estáticos podem ser subdivididos indefinidamente, por isso, os estados não apresentam granularidade. Essa diferenciação subsidia a hipótese de que as situações podem ser vistas como sendo compostas por conjuntos de átomos dinâmicos [- homogêneos] e/ou estáticos [+ homogêneos].

A propriedade da duratividade é responsável pela diferenciação entre situações [- durativas], como os achievements, constituídos por um único átomo dinâmico seguido de um átomo estático que instancia o ponto de culminação atingido pela realização da situação, e situações [+ durativas] como os accomplishments, que envolvem um conjunto de átomos dinâmicos seguidos de um átomo estático. Os accomplishments diferenciam-se das atividades também [+ durativas] e constituídas por um conjunto de átomos dinâmicos - por apresentarem um ponto de culminação estático como resultado da realização da situação, ao contrário das atividades. A duratividade deve ser entendida como estritamente operacional, já que qualquer situação, por mais breve que seja, apresenta certa duração.

A proposta de classificação de Bertinetto (2001) para o aspecto inerente ao verbo, ao considerar três propriedades das classes acionais, consegue minimizar os efeitos da aparente convergência aspectual entre telicidade $\rightarrow$ perfectividade e atelicidade $\rightarrow$ imperfectividade

O traço de aspecto inerente parece ser determinante para a escolha entre as formas de IMP e PPROG na expressão de passado imperfectivo. Bonomi (1998), no italiano, aponta os efeitos do aspecto inerente na possibilidade de IMP e PPROG funcionarem como equivalentes semânticos, como em (5) e (6) (BONOMI, 1998, p.3).

(5) Quando Miles Davis entrò al Village Vanguard, Bill Evans suonava in um trio con Scott La Faro e Paul Motian. [Quando Miles Davis entrou (passado, perfectivo) no Village Vanguard, Bill Evans jogava (passado, imperfectivo) em um trio com Scott La Faro e Paul Motian.] (BONOMI, 1998, p.3) 
(6) Quando Miles Davis entrò al Village Vanguard, Bill Evans stava suonando in um trio con Scott La Faro e Paul Motian. [Quando Miles Davis entrou (passado, perfectivo) no Village Vanguard, Bill Evans estava jogando (passado, imperfectivo) em um trio com Scott La Faro e Paul Motian.]

No italiano, IMP e PPROG têm a mesma propriedade semântica quando expressam passado imperfectivo ${ }^{5}$ Funcionariam como equivalentes? Bonomi (1998) sugere uma resposta negativa, baseada em uma investigação cuidadosa dos dados. Considerem-se os pares de (7), (8) e (9) (BONOMI, 1998, p.6).

(7a) Ieri alle tre Leo stava correndo nel parco. [Ontem às três Leo estava correndo no parque.]

(7b) Ieri alle tre Leo correva nel parco. [Ontem às três Leo corria no parque.]

(8a) Ieri alle tre Leo stava dimostrando un teorema. [Ontem às três Leo estava demonstrando um teorema.]

(8b) Ieri alle tre Leo dimostrava un teorema. [Ontem às três Leo demonstrava um teorema.]

(9a) Ieri alle tre Leo stava raggiungendi la vetta Della montagna. [Ontem às três Leo estava alcançando o topo de uma montanha.]

(9b) Ieri alle tre Leo raggiungeva la vetta Della montagna. [Ontem às três Leo alcançava o topo de uma montanha.]

No par (7), correr é um predicado de atividade, e as duas frases são equivalentes, expressando passado imperfectivo. A ideia é que a atividade de correr estava em curso às 3 horas da tarde. Como no italiano, com verbos de atividade, não parece haver problemas no intercâmbio de IMP e PPROG, no português, como ilustram (10) e (11).

(10) "Na época que eu mais precisei dele, que eu mais precisava de um apoio, foi quando a minha mãe morreu." (SC FLP 03).

(11) "Aí também foi na época que a gente voltou, a gente estava precisando economizar pra começar nossa vida." (SC FLP 01).

O valor de passado imperfectivo com predicados accomplishment, como demonstrar um teorema, no par (8), com PPROG é perfeitamente natural e espontâneo, mas em (8b), com IMP, é possível, mas não é o mais natural, como é em

\footnotetext{
Bonomi (1998) chama esse valor de leitura progressiva do imperfectivo. Entretanto, a função semântica pode ser considerada como a mesma de passado progressivo, como atestam os excertos do português que ilustram a análise.
} 
(8a). Porém, de acordo com Bonomi (1998, p.7), ampliando para outros contextos, o valor de passado imperfectivo de verbos do tipo accomplishment com IMP é possível, como ilustra o par (12):

(12a) Lo studente che dimostrava un teorema alla lavagna fu interrotto dalla campanella. [O estudante que demonstrava um teorema no quadro foi interrompido pelo sinal.]

(12b) L'auto percorreva il suo terzo giro quando il motore si ruppe. [O carro corria sua terceira volta quando o motor quebrou.]

Considerando que a interpretação de passado imperfectivo do IMP é aceitável com predicados do tipo accomplishment, como ilustrado no par (12), a interpretação de (8b) é válida, e IMP e PPROG também podem ser equivalentes. No português, a ocorrência de IMP em predicados do tipo accomplishment também é possível, como ilustra (13).

(13) "Era dez da noite, a mãe fazia a janta, quando a gente recebeu a notícia que ele se acidentou." (SC FLP MBC 23).

Já com o par (9), em que IMP e PPROG ocorrem com verbos do tipo achievement, a leitura de passado imperfectivo não é possível, e de acordo com Bonomi (1998), no italiano, as formas não podem ser consideradas equivalentes; pode-se dizer o mesmo para o português. ${ }^{6}$ Considerando o valor de passado imperfectivo, Bonomi (1998) conclui que, com predicados de atividade, IMP e PPROG são intercambiáveis, sem particular variação de sentido; com predicados accomplishment, IMP e PPROG podem ser intercambiáveis, dependendo do contexto; e em predicados achievement, a interação com IMP e PPROG resulta em accomplishments. Aparentemente, predicados de estado não são compatíveis com o valor de passado imperfectivo; Ilari e Mantoanelli (1983), por exemplo, afirmam que a perífrase estar + Vndo é compatível apenas com alguns tipos de predicados estativos, e por isso, casos de PPROG com verbos de estado podem ser encontrados.

(14) "Quando eu comecei a parar pra pensar que tipo de vida que eu estava levando, eu estava achando assim: 'Meu Deus, eu sou tão esquisita', eu fiquei pensando comigo assim, né?" (SC FLP FAP 03).

(15) "A gente, criança e estava imaginando, achava que ele estava lá." (SC FLP FAP 01).

De acordo com Bertinetto, Ebert e De Groot (2000, p.534), a combinação entre predicados do tipo achievement e aspecto progressivo resulta em uma leitura aspectual iminencial, sugerindo que o evento pode acontecer a seguir, mas que no momento de referência ainda não tinha ocorrido. 
Em (14), estava achando é um predicado de estado e que codifica uma situação passada imperfectiva. O mesmo vale para (15), tanto para o predicado com PPROG como para o predicado com IMP. Atividades, accomplishments e estados têm em comum o traço [+ duratividade], de acordo com a classificação de Bertinetto (2001).

O aspecto inerente, que se manifesta pelas classes acionais, é um traço que é associado ao item lexical. Porém, de acordo com Bertinetto (2001), as classes acionais são aplicadas a um predicado considerando que o predicado deve ser visto em sua estrutura argumental. Enquanto desenhar é sempre uma atividade [+ dur.; + din.; + hom.], desenhar um círculo é um accomplishment [+ dur.; + din..; - hom.]. A natureza dos determinantes também é relevante, já que desenhar [um, três, os círculos] é um accomplishment, mas desenhar círculos é novamente uma atividade. Do mesmo modo, João caiu é um achievement [- dur.; + din..; - hom.], enquanto as frutas caíram ao longo da estrada [durante toda a viagem] é uma atividade [+ dur.; + din..; + hom.]. Um dado predicado pode ser relacionado a mais de uma classe acional, dependendo da sua composição argumental. Em termos de operações em traços de classes acionais, o único traço que não se altera é o [dinamismo]: não existe operação, seja no nível interno da aspectualidade (argumentos) ou no nível externo (aspecto gramatical, adjuntos e contexto) que transforme situações [+ dinâmicas] em situações [- dinâmicas].

Na variação da expressão do passado imperfectivo, o aspecto inerente ao verbo foi um dos fatores apontados como significativos estatisticamente para a determinação da escolha entre as formas IMP e PPROG, ilustradas em (1) e (2) na introdução. A variável "aspecto inerente do verbo" tem se mostrado significativa em fenômenos de variação em categorias verbais, como apontam os estudos de Coan (1997), para a variação entre o pretérito perfeito e o pretérito mais-queperfeito na expressão do passado anterior, e Mendes (2005), para a variação entre estar + gerúndio e ter + particípio na expressão de aspecto imperfectivo durativo e iterativo. Ambos os autores partem da proposta de classificação de tipos de verbos de Vendler (2005). Porém, como visto acima, os tipos de Vendler (2005) podem ser desdobrados em traços, como sugerem Rothstein (2004) e Bertinetto (2001).

A hipótese para o controle desse grupo de fatores é fundamentada na hipótese de Bonomi (1998) para o italiano:

a) com predicados de atividade, IMP e PPROG são intercambiáveis, sem particular variação de sentido;

b) com predicados accomplishment, IMP e PPROG podem ser intercambiáveis, dependendo do contexto; 
c) em predicados achievement, a interação com IMP e PPROG resulta em accomplishments;

d) predicados estativos são compatíveis com poucos casos de PPROG (ILARI; MANTOANELLI, 1983).

O controle dos traços de Bertinetto (2001) tem por objetivo refinar o controle dos tipos de verbo de Vendler (2005).

Para verificar tais hipóteses, foi constituído um corpus composto por 36 entrevistas do Banco de Dados VARSUL relativas à cidade de Florianópolis, Santa Catarina, de onde foram coletadas 882 ocorrências da função semântico-discursiva "passado imperfectivo", tal como apresentada no início deste texto, das quais 546 são realizadas pela forma IMP e 336 são realizadas pela forma PPROG. Os dados foram submetidos a tratamento estatístico nos moldes da sociolinguística variacionista, com o cálculo de percentuais e pesos relativos, com o programa GoldVARB X (SANKOFF; TAGLIAMONTE; SMITH, 2005). Para refinar a análise, foram realizadas duas rodadas para testar a influência do aspecto inerente na variação entre IMP e PPROG, com a amalgamação de fatores. Na primeira rodada, foi considerada a proposta de classificação aspectual de Vendler (2005), estados, atividades, accomplishments e achievements; e, na segunda rodada, a de Bertinetto (2001), composta pela articulação entre os traços de [duratividade], [dinamicidade] e [homogeneidade]. Vejamos, pois, os resultados.

\section{Aspecto na perspectiva de Vendler (2005)}

Primeiramente, observe-se a clássica proposta de classificação aspectual de Vendler (2005), cujos resultados quantitativos para o corpus analisado são apresentados na tabela 1.

Os dados foram analisados em três conjuntos: a análise geral, que considera todas as ocorrências da amostra; a análise que considera apenas o aspecto durativo, valor aspectual mais propício à variação entre IMP e PPROG; e a análise que considera o aspecto durativo em pares mínimos (contexto idêntico - mesmo item lexical - em que duas ou mais formas podem ocorrer, ou seja, contextos em que as formas têm o mesmo significado referencial). Os resultados são apresentados em função de IMP como valor de aplicação, e os fatores estão ordenados em função da gradação de marcação, explicitada mais adiante.

As três análises (análise geral, aspecto durativo e aspecto durativo em pares mínimos) apresentam valores relativamente estáveis, tanto em termos de percentuais como em termos de pesos relativos. A distribuição dos resultados é escalar: estados tendem a favorecer o uso de IMP (peso relativo na casa de 0,60, 
variando entre 0,63 no conjunto mais específico a 0,68 no conjunto genérico), ao passo que atividades levemente restringem, com pesos relativos oscilando entre 0,46 e 0,41, e accomplishments restringem ainda mais IMP na expressão de passado imperfectivo, com pesos relativos entre 0,32 e 0,28. O caminho inverso pode ser traçado para PPROG: estados restringem o uso da forma, enquanto atividades e accomplishments favorecem o seu uso.

Tabela 1 - Valores de IMP para a classificação aspectual conforme a proposta de Vendler (2005)

\begin{tabular}{lccc}
\hline & Peso Relativo & Apl./total \\
\hline & \multicolumn{3}{c}{ Análise geral } \\
Aspecto do predicado & \multicolumn{3}{c}{. } \\
Estado & 0,68 & 78,4 & $240 / 306$ \\
Atividade & 0,46 & 57,1 & $197 / 345$ \\
Accomplishment & 0,32 & 47,2 & $109 / 231$ \\
& \multicolumn{3}{c}{ Aspecto durativo } \\
Estado & 0,65 & 78,4 & $221 / 282$ \\
Atividade & 0,41 & 53,4 & $133 / 247$ \\
Accomplishment & 0,28 & 35,6 & $31 / 87$ \\
& \multicolumn{3}{c}{} \\
Estado & Aspecto durativo em pares mínimos \\
Atividade & 0,63 & 80,1 & $181 / 226$ \\
Accomplishment & 0,42 & 56,0 & $117 / 207$ \\
\hline
\end{tabular}

Fonte: Autoria própria.

Esses resultados apontam que o tipo do predicado, de acordo com a classificação de Vendler (2005), é fator fortemente motivador na escolha da forma para a expressão do passado imperfectivo: i) estados tendem a selecionar a forma IMP; ii) accomplisments tendem a selecionar a forma PPROG.

A hipótese de Bonomi (1998) para o italiano encontra respaldo nos resultados quantitativos do português:

a) com atividades, IMP e PPROG são intercambiáveis, embora haja leve tendência à escolha de PPROG (peso relativo oscilando entre 0,54 e 0,58);

b) com accomplishments, IMP e PPROG podem ser intercambiáveis, dependendo do contexto, com tendência à escolha de PPROG (peso relativo oscilando entre $0,68$ e 0,72$)$;

c) com achievements, IMP e PPROG não são intercambiáveis, dado que a interação entre passado imperfectivo e este tipo de predicado resulta em accomplishments; 
d) com predicados estativos, IMP e PPROG também são intercambiáveis, embora haja tendência à escolha de IMP (peso relativo oscilando entre 0,68 e 0,63).

No espanhol, de acordo com Givón (2001), a interação entre o aspecto inerente ao verbo e as formas de imperfectivo passado - aspecto interno, na perspectiva de Wachowicz (2003) - resulta em casos de ambiguidade aspectual. O espanhol tem gramaticalizadas duas formas de imperfectivo no passado, o imperfecto e o progressivo, que se opõem ao pretérito [perfeito]. A interação entre o aspecto inerente do verbo e o morfema gramatical (IMP ou PPROG) permite diferentes leituras aspectuais, dentro do campo da imperfectividade.

Verbos compactos (achievements) costumam ocorrer com aspecto perfectivo; quando combinados ao aspecto imperfectivo, tornam-se construções marcadas e tendem a codificar aspecto iterativo. Mas, como aponta Givón (2001, p.290), no espanhol (e também no português), a relação entre o tipo de verbo marcado (os compactos) e o aspecto imperfectivo gera ambiguidade aspectual, entre habitual e iterativo, como em (16):

(16) Lo-tiró (PRET)/Ele atirou em X (uma única vez).

Lo-tiraba (IMP)/Ele atirava em X.

Ele atirava repetidamente em X (intervalo definido) - iterativo.

Ele atirava várias vezes em X (intervalo indefinido) - habitual.

Lo-estaba tirando (PPROG)/Ele estava atirando em $\mathbf{X}$ várias vezes - iterativo.

Givón (2001) salienta que a combinação entre verbos do tipo accomplishment e aspecto gramatical imperfectivo é também pouco frequente. Com IMP, a interpretação habitual-iterativa é possível. Com PPROG, a ênfase fica no sentido de duração, ou seja, de processo precedendo a fronteira final, como em (17).

(17) Llegó a la casa (PRET)/Ele chegou em casa (uma única vez).

Llegaba a la casa (IMP)/Ele chegava em casa (iterativo, habitual).

Estaba llegando a la casa (PPROG)/Ele estava chegando em casa (processo em andamento).

A combinação entre verbos de atividade/processo com aspecto imperfectivo também gera ambiguidade, como em (18) (GIVÓN, 2001, p.291):

(18) Lo-leó (PRET)/Ele leu (e acabou).

Lo-leía (IMP).

Ele lia (diferentes vezes).

Ele lia (situação estendida)/Lo-estaba leyendo (PPROG).

Ele estava lendo (situação estendida). 
Verbos estativos tendem a rejeitar a interação com aspecto perfectivo. Rejeitam também a interpretação progressiva, talvez porque este tipo de verbo já foca a situação em andamento. Os verbos estativos retêm sua aspectualidade inerente no imperfectivo, que é seu mais comum aspecto não-marcado no passado, como em (19) (GIVÓN, 2001, p.292):

(19) Conocío (*bien) a Juan (PRET).

Conheci (?bem) João.

Conocía bien a Juan (IMP).

Conhecia bem João.

*Estaba conociendo (bien) a Juan (PPROG).

(?) Estava conhecendo bem João.

O traço comum a estados, atividades e accomplishments é a duratividade; o traço [-duratividade] barra o aspecto imperfectivo, e pode ser visto na perspectiva da marcação. Considerando a convergência entre o aspecto inerente e o aspecto gramatical, Givón (2001) propõe uma escala de (im)perfectividade para os verbos em função do critério da marcação. A (im)perfectividade é determinada a partir da interação entre dois traços, fronteira temporal (nítida versus difusa) e duração (curta versus longa):

a) verbos compactos (achievements): em um extremo da escala de perfectividade, estão os verbos que codificam situações cujas fronteiras inicial e final são definidas e coincidentes.

b) verbos accomplishments: codificam a completação de uma situação. É uma situação com a fronteira final nítida, cuja duração é maior do que a dos verbos compactos.

c) verbos de atividade: a situação codificada por esse tipo de verbo pode ter as fronteiras inicial e final definidas, mas o foco está na duração.

d) verbos de estado: no outro extremo da escala de (im)perfectividade, verbos de estado focam a duração do evento, sem delimitação das fronteiras.

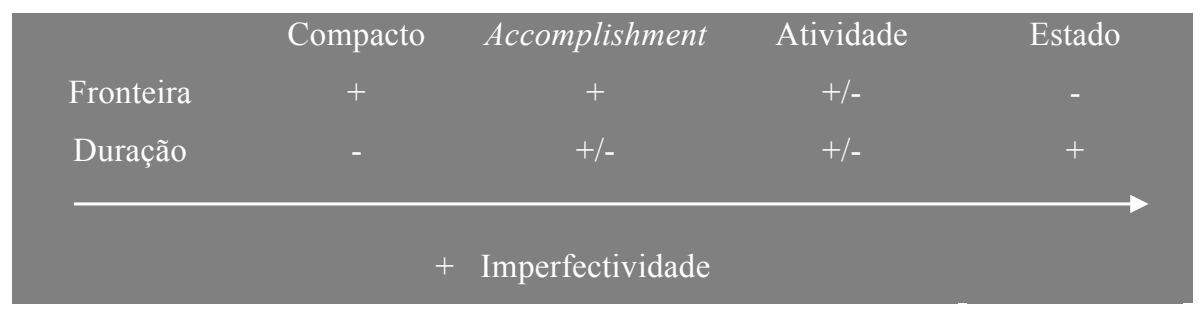

Quadro 3 - Escala de marcação de im(perfectividade)

Fonte: Givón (2001, p.287-288). 
Verbos do tipo accomplishment podem ter maior ou menor duração, sendo mais usual não haver foco na duração. Verbos de atividade podem apresentar tanto o traço de fronteira como o de duração, sendo definido em função da perspectiva comunicativa, que determina a escolha do aspecto gramatical. No plano da perfectividade, a combinação entre aspecto perfectivo e verbos de estado é a relação aspectual mais marcada; e a combinação entre aspecto perfectivo e verbos compactos, a menos marcada. Como o aspecto gramatical imperfectivo é o aspecto marcado, a correlação traçada entre as combinações de aspecto gramatical e aspecto inerente inverte a polaridade quanto à marcação: no plano da imperfectividade, a combinação entre aspecto imperfectivo e verbos de estado seria a relação aspectual menos marcada, e mais previsível; e a combinação entre aspecto imperfectivo e verbos compactos, a mais marcada, e menos previsível.

A escala de (im)perfectividade e marcação de Givón (2001) se verifica na distribuição das ocorrências de IMP expressando passado imperfectivo: estados menos marcados e mais previsíveis são os que mais contabilizam ocorrências, seguidos escalarmente por atividades e accomplishments, até a não ocorrência de achievements, mais marcados e menos previsíveis. Porém PPROG apresenta distribuição contrária ao contínuo da marcação: estados, em princípio, menos marcados e mais previsíveis, contabilizam menos ocorrências, e accomplishments, relativamente mais marcados e menos previsíveis, são os que mais contabilizam ocorrências.

Se ambas as formas são responsáveis pela expressão da imperfectividade, o que explica a incongruência? Essa questão é retomada mais adiante. Antes, vejam-se os resultados relativos à classificação aspectual de Bertinetto (2001) que desdobra as classes de Vendler (2005) em três traços - e que podem ajudar a elucidar a incongruência dos contínuos de marcação de IMP e PPROG na expressão de passado imperfectivo.

\section{Aspecto na perspectiva de Bertinetto (2001)}

Como visto, a classificação aspectual de Vendler (2005) pode ser desdobrada em traços semânticos que se articulam e manifestam o valor aspectual. Bertinetto (2001) sugere três traços semânticos que estão associados à expressão de aspecto inerente: [duratividade], [dinamismo] e [homogeneidade]. O controle do aspecto por meio de feixe de traços permite verificar qual o menor componente aspectual que atua na variação entre IMP e PPROG na expressão de passado imperfectivo. O quadro 4 apresenta os feixes de traços aspectuais pertinentes à expressão do passado imperfectivo (achievements, ao interagirem com o aspecto gramatical, resultam em accomplisments). 


\begin{tabular}{lccc}
\hline & Durativo & Dinâmico & Homogêneo \\
\hline Estados & + & - & + \\
Atividades & + & + & + \\
Accomplishments & + & + & - \\
\hline
\end{tabular}

Quadro 4 - Arranjo dos traços aspectuais de IMP e PPROG

Fonte: Bertinetto (2001, p.179).

Tabela 2 - Valores de IMP para a classificação aspectual conforme a proposta de Bertinetto (2001)

\section{Peso Relativo $\quad \% \quad$ Apl./total}

\begin{tabular}{lccc} 
& Peso Relativo & $\%$ & Apl./total \\
\hline & \multicolumn{3}{c}{ Análise geral } \\
$\begin{array}{l}\text { Duratividade } \\
+\end{array}$ & $* * *$ & 100 & $882 / 882$ \\
- & $* * *$ & 0 & $0 / 0$ \\
Dinamismo & & & \\
+ & 0,40 & 52,8 & $297 / 563$ \\
- & 0,66 & 78,1 & $249 / 319$ \\
Homogeneidade & & & \\
+ & $(0,53)$ & 66,6 & $424 / 637$ \\
- & $(0,41)$ & 49,8 & $122 / 245$
\end{tabular}

Aspecto durativo

Duratividade

$+$

Dinamismo

$+$

Homogeneidade

$+$

$-$

Duratividade

$+$

Dinamismo

$+$

Homogeneidade

\begin{tabular}{cccc}
+ & 0,52 & 68,6 & $295 / 430$ \\
- & 0,35 & 41,5 & $27 / 65$ \\
\hline
\end{tabular}

Fonte: Autoria própria 
Assim como no aspecto na perspectiva de Vendler (2005), os dados foram analisados em três conjuntos (análise geral, aspecto durativo e pares mínimos). Os resultados da tabela 2 apontam que o traço [duratividade] tem comportamento categórico na expressão do aspecto imperfectivo, o que já fora confirmado com a ocorrência de atividades, accomplishments e estados, que têm em comum o traço [+ duratividade], de acordo com a classificação de Bertinetto (2001), no quadro 4.

Para o traço [homogeneidade], o valor de 0,41 indica leve tendência ao uso de PPROG na presença do traço [- homogêneo]. A tendência é ressaltada no modelo de aspecto durativo e pares mínimos, em que o peso relativo para o traço [- homogêneo] de 0,35 indica restrição ao uso de IMP e favorecimento de uso de PPROG. O traço [+ homogêneo], oscilando entre 0,53 e 0,52, está muito próximo do ponto neutro, indicando que o traço não exerce influência significativa na variação entre as formas para a expressão do passado imperfectivo.

O traço [dinamismo] indica tendências opostas para a expressão do passado imperfectivo. Na presença do traço [+ dinâmico], a forma PPROG é favorecida, com peso relativo entre 0,60 (0,40 para IMP) e 0,64 (0,36 para IMP), enquanto na presença do traço [- dinâmico], a forma IMP é favorecida, com pesos relativos oscilando entre 0,66 (0,34 para PPROG) e 0,60 (0,40 para PPROG).

A duratividade é uma propriedade temporal definidora do passado imperfectivo, logo não poderia haver ocorrências de IMP ou PPROG nesse valor aspectual com o traço [- durativo].

A comparação dos traços aspectuais que atuam na expressão de passado imperfectivo, apresentada no quadro 5, aponta para o papel central que o dinamismo exerce para motivar a escolha das formas.

\begin{tabular}{lcc}
\hline & IMP & PPROG \\
\hline Durativo & + & + \\
Dinâmico & - & + \\
Homogêneo & $-/+$ & - \\
\hline
\end{tabular}

Quadro 5 - Tendências de uso de IMP e PPROG na expressão do passado imperfectivo quanto aos traços aspectuais

Fonte: Autoria própria.

O traço [dinamismo] exerce forte influência na escolha das formas para a expressão dos valores aspectuais do passado imperfectivo. Quais as motivações para a atuação do dinamismo na variação entre as formas? Entender o processo de gramaticalização de PPROG pode trazer pistas para elucidar a questão. 


\section{Aspecto, variação/mudança e marcação}

Para entender o efeito do traço [dinamismo] na variação entre IMP e PPROG na expressão do passado imperfectivo, é preciso traçar um retrospecto da trajetória de gramaticalização da forma PPROG e seu valor progressivo. Uma explicação sobre a origem diacrônica de PPROG pode auxiliar na interpretação da sua distribuição sincrônica.

Assumindo a escala hierárquica do aspecto de Comrie (1976), Bertinetto (2000) traça um contínuo para dar conta da mudança do progressivo ao imperfectivo genérico nas línguas românicas. O quadro 6 apresenta a escala de valores da forma PPROG, partindo da sua origem latina como estativo durativo, passando pelo durativo, focalizado até a perda do sentido progressivo. No português, o progressivo predominantemente situa-se entre (iv), progressividade III, e (v), pura imperfectividade.

(i) puramente locativo = estativo, durativo

(ex.: o sentido observado em exemplos latinos)

(ii) progressividade $I=$ residualmente locativo, durativo, aspectualmente neutro

(ex.: perífrases progressivas baseadas no verbo 'vir', que preserva algum tipo de orientação dêitica)

(iii) progressividade $I=$ durativo, aspectualmente neutro

(ex.: perífrases progressivas baseadas no verbo "ir")

(iv) progressividade $I I I=$ focalizada, estritamente imperfectiva

(ex.: italiano "stare + gerúndio")

(v) pura imperfectividade $=$ perda da característica progressiva

(ex.: possibilidade observada em variantes não-standard do espanhol da América Latina)

Quadro 6 - Do progressivo ao imperfectivo nas línguas românicas

Fonte: Bertinetto (2000, p.332).

Do ponto de vista formal, a origem de PPROG está no português arcaico. A análise de Mattos e Silva (2001) de construções verbais com ser, jazer, estar, andar e ir + gerúndio, nos séculos XIII a XV, sugere que os verbos auxiliares passaram por processo de gramaticalização, com a perda do valor lexical do candidato a auxiliar que, combinado às formas nominais do verbo principal, tornouse "suporte para as marcas de modo/tempo e número pessoa" (MATTOS E SILVA, 2001, p.62) da construção. Dentre as construções candidatas, a perífrase estar + gerúndio caracteriza-se pela continuidade no processo de gramaticalização e pela produtividade do uso do recurso na língua. Mendes (1999) postula o seguinte percurso de gramaticalização para a perífrase estar + gerúndio no português (quadro 7): 


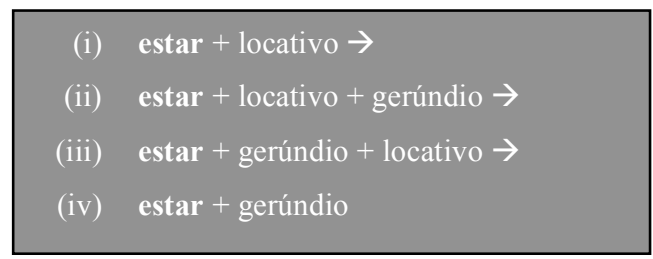

Quadro 7 - Contínuo de gramaticalização para a perífrase estar + gerúndio Fonte: Adaptado de Mendes (1999, p.69).

Apesar do processo de gramaticalização, a perífrase estar + gerúndio apresenta restrição de coocorrência com o verbo estar: não há registro de ocorrências de está ${ }_{\text {[auxiliar] }}$ estando $_{\text {[verbo pleno] }}{ }^{7}$

Do ponto de vista funcional, dada a diversidade de valores que a perífrase estar + gerúndio assumiu no português - como pode ser visto nos estudos de Wachowicz (2003) e Ilari e Mantoanelli (1983) -, a forma tem despertado o interesse para abordagens. Basicamente, a forma de presente do indicativo é a que tem recebido mais atenção. O estudo de Ilari e Mantoanelli (1983), por exemplo, apresenta uma descrição dos valores que estar + gerúndio pode assumir no português, mas usa apenas um exemplo com IMP, transcrito em (20).

(20) "Quando o encontrei, estava trabalhando na Bosch." (ILARI; MANTOANELLI, 1983, p.27, grifo nosso).

O exemplo (20) ilustra o passado progressivo (PPROG). O termo "passado" do rótulo refere-se a uma situação que ocorre em um momento anterior ao de fala. Já o termo progressivo é definido de acordo com Bybee, Perkings e Pagliuca (1994), segundo os quais o progressivo codifica uma situação em andamento em relação ao tempo de referência em predicados dinâmicos. Bybee (2003) aponta que o progressivo deriva de (i) verbos locativos, (ii) da construção estar + forma não infinitiva - o que é comprovado pelos estudos de Mendes (1999) e de Mattos e Silva (2001) - e (iii) também de verbos de movimento, como em algumas línguas românicas. A perífrase estar + gerúndio vem se gramaticalizando não só no português, mas nas línguas românicas. Parece ser uma tendência sistemática,

\footnotetext{
A incompatibilidade com o verbo estar não é a única restrição que a perífrase estar + gerúndio apresenta. Existe uma restrição quanto ao modo verbal, apontada por Ilari e Mantoanelli (1983): a perífrase estar + gerúndio não ocorre com o imperativo (Edair Gorski ilustra a ocorrência de estar + gerúndio no imperativo com "Esteja chegando aqui sem falta às 15 horas"; eu particularmente não compartilho desta opinião; Já Ina Emmel ilustra com "Quando o chefe chegar, esteja trabalhando!", a qual me convence da possibilidade de ocorrência de progressivo com imperativo, derrubando o argumento de Ilari e Mantoanelli) (informação verbal). Outras restrições mais brandas são verificadas na combinação entre tempo verbal e a base do verbo. Porém, dentre as combinações possíveis, as formadas com presente do indicativo e com IMP são as que menos sofrem restrições.
} 
que evidencia as hipóteses de Bybee (2003) e também Bybee, Perkings e Pagliuca (1994).

O quadro 8 apresenta uma classificação das formas perifrásticas nas línguas românicas. As formas chamadas de progressivo não-cinético são as constituídas por um verbo auxiliar estático mais uma forma nominal, como estar no catalão, espanhol, português e italiano.

\begin{tabular}{|c|c|c|c|}
\hline & Progressivo não-cinético & Progressivo cinético & Formas marginais \\
\hline Catalão & estar + gerúndio & añar + gerúndio & $?$ \\
\hline Espanhol & estar + gerúndio & ir/andar/venir + gerúndio & $?$ \\
\hline Francês & - & aller + gerúndio & être en train de + infinitivo \\
\hline Italiano & $\begin{array}{l}\text { stare }+ \text { gerúndio } \\
\text { stare } a+\text { infinitivo }\end{array}$ & andare/venire + gerúndio & essere dietro $a+$ infinitivo \\
\hline Português & $\begin{array}{l}\text { estar }+ \text { gerúndio } \\
\text { estar } a+\text { infinitivo }\end{array}$ & ir / vir + gerúndio & $?$ \\
\hline Romeno & 一 & - & $\begin{array}{l}\text { a fi în curs de a }+ \\
\text { infinitivo }\end{array}$ \\
\hline
\end{tabular}

Quadro 8 - Classificação das formas perifrásticas nas línguas românicas

Fonte: Bertinetto (2000, p.601).

As formas chamadas de progressivo cinético são as constituídas por um verbo auxiliar de movimento mais gerúndio, como andar, ir e vir, no catalão, espanhol, francês, italiano e português. Há ainda as línguas que possuem formas marginais, como o francês e o romeno. As formas marginais são assim chamadas por não se originarem das construções que Bybee, Perkings e Pagliuca (1994) apontam.

A forma de progressivo envolvendo um auxiliar estático sempre deriva de uma construção que originalmente envolvia um elemento com sentido locativo (menos frequentes, os verbos de movimento também originam progressivo, como o auxiliar andar). O exemplo (21), dado Bybee, Perkings e Pagliuca (1994, p.133) por Dwigth Bolinger, tenta deixar clara a origem locativa do progressivo.

(21) - Onde estava Lou?

- (estava) tomando banho.

Lou não pôde atender ao telefone porque estava tomando banho.

O progressivo, ainda de acordo com Bybee, Perkings e Pagliuca (1994), implica envolvimento do sujeito com a atividade (agente/objeto afetado). A estrutura do progressivo é (implícita ou explícita): um agente $>>$ localizado espacialmente > > no meio de $>>$ uma atividade $>>$ em relação ao tempo de referência. 
Retomando em (22) o exemplo de Ilari e Mantoanelli (1983), verifica-se a estrutura do progressivo. Existe um agente implícito, é introduzido pelo pronome o da oração subordinada, que está localizado espacialmente na Bosch. Não há indicação sobre os extremos temporais da situação de trabalhar, o morfema de IMP indica que a situação ocorreu em um momento anterior ao da fala. A situação tem limites temporais (início e fim), porém o progressivo tem como característica codificar o valor de "meio", andamento da situação.

(22) Quando o encontrei $i_{i}{ }_{\text {[agente] }}$

estava trabalhando

na Bosch espacial]

Esse é o uso prototípico do progressivo no português (e também em outras línguas). O dinamismo da situação - a agentividade do sujeito - é um resquício do processo de gramaticalização da construção estar + Vndo. Observe-se a trajetória proposta por Torres Cacoullos (2001) para o espanhol do México: a perífrase estar + gerúndio, diacronicamente, perdeu o sentido locativo espacial estrito por conta de esvaziamento semântico decorrente da gramaticalização, assim como no português, e expandiu o sentido aspectual para imperfectivo. Na trajetória de gramaticalização, quanto às propriedades semânticas do auxiliar, o valor aspectual progressivo perde o sentido específico, assumindo o sentido genérico de imperfectivo. Torres Cacoullos (2001) evidencia que, no espanhol falado no México, as construções estar + Vndo e andar + Vndo recobrem um leque de usos no território do imperfectivo, do progressivo ao habitual, funcionando, inclusive, como variantes de uma variável socialmente estratificada.

estar + Vndo

(i) Sujeito está localizado espacialmente em ação simultaneamente com a referência.

$\downarrow$

(ii) Sujeito está localizado $\Theta$ em ação simultaneamente com 0 momento de referência.

$\downarrow=$ progressivo

(iii) Sujeito está $\quad$ em ação $\quad \Theta=$ imperfectivo genérico

Quadro 9 - Esvaziamento semântico de estar + gerúndio no espanhol

Fonte: Torres Cacoullos (2001, p.447).

No quadro 9, o sentido locativo de (i) é esvaziado, levando à perda do sentido espacial. Com a perda do traço espacial, a construção tem seu contexto de uso ampliado, adentra no domínio temporal (aspectual), originando o progressivo (ii) e o imperfectivo genérico, (iii). Por imperfectivo genérico, Torres Cacoullos (2001) refere-se a uma gama de usos, incluindo progressivo, contínuo, frequentativo e também o habitual. O rótulo imperfectivo genérico, como já mencionado, é determinado pelas relações de dominância estabelecidas na proposta de 
classificação aspectual de Comrie (1976) e pode recobrir qualquer um dos valores aspectuais do imperfectivo.

Os estudos de Bybee, Perkings e Pagliucca (1994) e de Torres Cacoullos (2001) explicam a importância do traço [dinamismo] na ocorrência de PPROG na expressão de passado imperfectivo. É uma reminiscência do processo de gramaticalização da forma estar + Vndo e que persiste na trajetória da forma PPROG. Hopper (1991, p.24), ao propor princípios da gramaticalização, fala da persistência: "quando uma forma sofre gramaticalização passando de lexical a gramatical, alguns traços de seu sentido lexical original tendem a continuar, e detalhes da sua história lexical podem refletir no condicionamento da sua distribuição gramatical". É o que está acontecendo com PPROG: um detalhe da sua história gramatical (quando funcionava como progressivo estrito) tem reflexo na sua distribuição nos contextos em que a forma já gramaticalizou o valor de passado imperfectivo, determinando a incongruência no contínuo da marcação para o aspecto imperfectivo no que se refere à PPROG (GIVÓN, 2001).

Apesar da possibilidade de IMP e PPROG expressarem o mesmo valor semântico-discursivo, a incongruência entre os contínuos de marcação (do menos ao mais marcado) para a interação entre aspecto inerente e IMP [estados > atividades > accomplishments > achievements] e o da interação entre aspecto inerente e PPROG [accomplishments > atividades > estados] se deve à persistência do traço de agentividade do sujeito na origem da forma inovadora - PPROG que ainda se mostra atuante, ao ponto de influenciar a escolha das formas em contextos onde o traço [dinamismo] é saliente, ou seja, em verbos accomplishment e atividade. ${ }^{8}$ Os dados estatísticos discutidos para o aspecto na perspectiva de Vendler (2005) e para o aspecto na perspectiva de Bertinetto (2001) respaldam a hipótese da persistência (HOPPER, 1991) e confluem com a tendência apontada por Torres Cacoullos (2001) no espanhol falado no México.

\section{Considerações finais}

Neste texto, buscou-se evidenciar indícios da ação dos princípios da persistência (HOPPER, 1991) e da marcação (GIVÓN, 2001) na gramaticalização das formas de expressão do passado imperfectivo no português. O controle do aspecto inerente ao verbo em um modelo quantitativo apontou que o traço aspectual [dinamismo] determina as associações entre formas na expressão do passado imperfectivo, por conta do histórico aspectual de PPROG, que trava relação direta com o traço [+ dinâmico], e IMP, associado com o traço [- dinâmico] por conta do

O traço [+/- agentividade] é indiretamente captado através do controle dos valores aspectuais, por meio da propriedade do dinamismo (BERTINETTO, 2001; WACHOWICZ, 2003). 
seu histórico de marcar distanciamento. A atuação do aspecto inerente ao verbo no passado imperfectivo em português configura uma situação de distribuição complementar: embora aparentemente intercambiáveis, as formas IMP e PPROG não podem ser consideradas como equivalentes semântico-discursivos, pois o traço [dinamismo] do verbo faz com que a escolha entre as formas seja direcionada.

Os princípios da marcação e da persistência mostram-se atuantes na trajetória de variação e mudança nas formas de expressão do passado imperfectivo. A marcação atua tentando evitar deixar os contextos carregados, distribuindo o peso cognitivo entre os elementos: se o contexto é mais marcado, elege uma forma menos marcada para compensar. A persistência funciona como uma espécie de trilha virtual que direciona o uso das formas no decorrer das camadas. Os princípios da marcação e da persistência atuam como motivações convergentes no processo de gramaticalização/variação das formas IMP e PPROG na expressão do passado imperfectivo no português.

FREITAG, R. M. K. Inherent aspect and past imperfective in Portuguese: action of the persistence and markedness principles. Alfa, Araraquara, v.55, n.2, p.477-500, 2011.

- ABSTRACT: The main argument in this paper is to present evidences of the action of the persistence principle (HOPPER, 1991) and the markedness principle (GIVÓN, 2001) on the grammaticalization of Portuguese past imperfective. From the quantitative point of view, the verb inherent aspect control shows that the aspectual feature [dynamism] determines the association between the forms in the expression of the past imperfective due to the PPROG and IMP aspectual histories, where the former is marked [+ dynamic] and the latter [- dynamic] for it also codes temporal distance. These results show that persistence and markedness may be considered converging motivations for the variation process in the expression of past imperfective.

- KEYWORDS: Past imperfective. Grammaticalization. Converging motivations.

\section{REFERÊNCIAS}

BERTINETTO, P. M. On a frequent misunderstanding in the temporal-aspectual domain: the 'perfective-telic confusion. In: CECCHETTO, C.; CHIERCHIA, G.; GAUSTI, M. T. (Ed.). Semantic interfaces: reference, anaphora and aspect. Stanford: CSLI, 2001. p.177-210.

. The progressive in Romance, as compared with English. In:DÄHL, O. (Ed.). Tense and aspect in the languages of Europe. Berlin: Mouton, 2000. p.559-664.

BERTINETTO, P. M.; EBERT, K.; DE GROOT, C. The progressive in Europe. In: DÄHL, O. (Ed.). Tense and aspect in the languages of Europe. Berlin: Mouton, 2000, p.517-558. 
BONOMI, A. Semantical remarks on the progressive reading of the imperfective. 1998. Disponível em:<http://www.filosofia.unimi.it/ bonomi/BONOMIBG211002. pdf $>$. Acesso em: 21 jul. 2010.

BYBEE, J. Cognitive processes in grammaticalization. In: TOMASELLO, M. (Ed.). The new psychology of language. New Jersey: Lawrence Erlbaum Associates, 2003. v.2, p.145-167.

BYBEE, J.; PERKIGNS, R; PAGLIUCA, W. The evolution of grammar. tense, aspect, and modality in the language of the world. Chicago: The University of Chicago Press, 1994.

CASTILHO, A. T. Aspecto verbal no português falado. In: ABAURRE, M. B.; RODRIGUES, A. (Org.). Gramática do português falado. Campinas: Ed. da Unicamp, 2003. v.8. p.83-121.

COAN, M. Anterioridade a um ponto de referência passado: pretérito (mais que) perfeito. 1997. 177f. Dissertação (Mestrado em Linguística) - Centro de Comunicação e Expressão, Universidade Federal de Santa Catarina, Florianópolis, 1997.

COMRIE, B. Aspect. Cambridge: Cambridge University Press, 1976.

FREITAG, R. M. K. Problemas teórico-metodológicos para o estudo da variação linguística nos níveis gramaticais mais altos. Matraga, Rio de Janeiro, v.16, n.24, p.115-132, 2009.

A expressão do passado imperfectivo no português: variação/ gramaticalização e mudança. 2007. 238f. Tese (Doutorado em Linguística) Centro de Comunicação e Expressão, Universidade Federal de Santa Catarina, Florianópolis, 2007.

GIVÓN, T. Syntax: an introduction. Amsterdam: John Benjamins, 2001.

HOPPER, P. On some principles in the grammaticalization. In: TRAUGOTT, E.; HEINE, B. (Ed.). Approaches to grammaticalization. Philadelphia: John Benjamins, 1991. v.1. p.17-35.

ILARI, R.; MANTOANELLI, I. As formas progressivas do português. Caderno de Estudos Linguísticos, Campinas, n.5, p.27-60, 1983.

MATTOS E SILVA, R. V. O português arcaico: morfologia e sintaxe. São Paulo: Contexto, 2001.

MENDES, R. B. Estar + gerúndio e ter + particípio: aspecto verbal e variação no português. 2005. 189f. Tese (Doutorado em Linguística) - Instituto de Estudos da Linguagem, Universidade Estadual de Campinas, Campinas, 2005. 
. A gramaticalização de estar + gerúndio no português falado. 1999. $112 \mathrm{f}$. Dissertação (Mestrado em Linguística) - Instituto de Estudos da Linguagem, Universidade Estadual de Campinas, Campinas, 1999.

PROJETO VARSUL. Variação Linguística na Região Sul do Brasil: banco de dados. Disponível em: < http://varsul.cce.ufsc.br/>. Acesso em: 21 jul. 2010.

ROTHSTEIN, S. Struturing events: a study in the semantics of lexical aspects. Oxford: Blackwell, 2004.

SANKOFF, D.; TAGLIAMONTE, S.; SMITH, R. Goldvarb X: a variable rule application for Macintosh and Windows, 2005. Mimeografado. Produção do Department of Linguistics of University of Toronto, Department of Mathematics of the University of Ottawa.

TORRES CACOULLOS, R. From lexical to grammatical to social meaning. Language in Society, Cambridge, v.30, p.443-478, 2001.

VENDLER, Z. Verbs and time. In: MANI, I.; PUSTEJOVSKY, J.; GAIZAUSKAS, R. (Ed.). The language of time: readings in temporal information processing. Oxford: Oxford University Press, 2005. p.21-32.

WACHOWICZ, T. C. As leituras aspectuais da forma do progressivo do português brasileiro. 2003. 221f. Tese (Doutorado em Linguística) - Faculdade de Filosofia, Letras e Ciências Humanas, Universidade de São Paulo, São Paulo, 2003.

Recebido em julho de 2010.

Aprovado em novembro de 2010. 